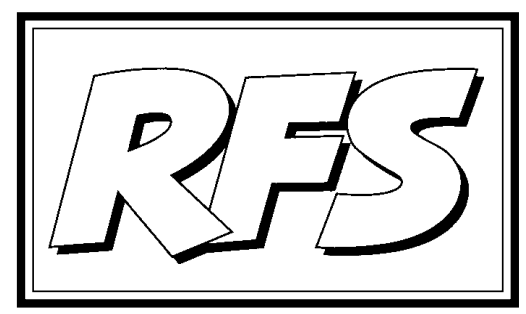

Revista de Fomento Social, 58 (2003), 559-570

\title{
Temores y esperanzas de una ciudad ${ }^{1}$
}

Carlo Maria MARTINI S.I. ${ }^{2}$

Hace más de quince años, con ocasión de la entrega de un reconocimiento similar de parte del alcalde de una gran ciudad italiana a Giuseppe Dossetti, figura que tiene un alto significado espiritual para mí, el homenajeado comenzaba su discurso de agradecimiento citando el Evangelio de Lucas:

1 Pronunciado el 28 de junio de 2002. Original: MARTINI C.M., Paure e speranze di una città. Discorso al Comune di Milano (28 giugno 2002), Centro Ambrosiano, Milano 2002, publicado en, (2002), Aggiornamenti Sociali 53, 688-696. Traducción del original italiano de J.M. Margenat con la colaboración de N. Castells. En el editorial de nuestra entrega de eneromarzo de 2003 hacíamos alusión a este discurso (p. 25). Debemos subsanar dos errores deslizados entonces: el discurso no era el tradicional de la fiesta de san Ambrosio, de 7 de diciembre, sino que estuvo motivado por la ocasión a que se hace referencia al comienzo del mismo; por otra parte, anunciábamos que sería publicado en la siguiente entrega de RFS, aunque finalmente haya sido en la de julio-septiembre. Sobre los discursos a la ciudad del cardenal Martini, cfr. B. SORGE, «Da cristiani in politica. II "decalogo' del Card. Martini. Per un riformismo nuovo», en, (2002), Aggiornamenti Sociali 53, 719-730. (N.d.t.).

2 Cardenal Arzobispo de Milán (1979-2002). 
«Cuidado cuando los hombres hablen bien de vosotros...»».Y seguía diciendo que «esta severa advertencia del Señor y Maestro», al principio, le había «retraído un poco para aceptar este honor, más allá de la conciencia de no tener títulos específicos para esta distinción». Se había decido a aceptar, sin embargo, por el simple hecho del ofrecimiento que le había hecho el alcalde «con tanta delicadeza y nobleza», que parecía exigirle «una respuesta positiva, serena, grata y cordial »4.

Sirviéndome de ese ejemplo, yo también me he atrevido a dar una respuesta similar ante la gentileza y amabilidad de la propuesta, porque está acabando mi servicio pastoral en Milán y por la gratitud que siento hacia toda la ciudad, ya que se me ha dado la posibilidad de vivir en ella más de veintidós años. Quiero pues agradecer vivamente al presidente del Consejo municipal $y$ al Alcalde sus palabras y su gesto, por esta gran medalla de oro que, como se ha dicho, «es signo del indisoluble afecto entre la ciudad y su obispo». Estas palabras traen al recuerdo y a la mente aquellas de san Ambrosio, en su famosa carta sobre las basílicas, que en las circunstancias actuales podríamos traducir: «iTemisteis acaso que quisiera abandonaros (...). No puedo, ni siquiera de lejos, pensar en olvidar esta Iglesia y esta ciudad (...) no os abandonaré nunca en el fondo de mi corazón»5. Lo que es como decir: «os llevaré conmigo allá donde vaya, incluso a J erusalén». Agradezco de corazón el gesto, pues, al que me ha ofrecido este regalo altamente simbólico, y con ello doy las gracias al Consejo municipal en pleno, que representa a toda la ciudad; en él están todos los ciudadanos de esta espléndida e industriosa metrópoli, que en todas las circunstancias, aún las dolorosas, antiguas y recientes, ha encontrado siempre y encuentra la fuerza para vencer los miedos, cultivar la esperanza y continuar obrando según los ideales de justicia y del bien común. La fuerza interior que anima a esta ciudad es la que me lleva a expresar algunas convicciones personales y reflexiones, precisamente sobre los temores y las esperanzas de la ciudad en el actual contexto.

3 LC 6:26.

4 Discurso del Archiginnasio, 22 de febrero de 1986. Giuseppe Dossetti, nacido en Génova en 1913, fue vicesecretario de la Democrazia Cristiana y líder de su ala izquierda. Más tarde fue sacerdote y fundó la comunidad monástica de Monteveglio, falleciendo en 1996 (N.d.t.).

5 «Metuistis ergo ne ecclesiam desererem? (...) Deserendae ecclesiae mihi voluntatem subesse non posse (...). Volens nunquam vos deseram» (Las citas de los textos latinos de San Ambrosio están en su original latino sólo en los casos en que la traducción castellana (y la del original italiano) nos son literales (N.d.r. de Aggiornamenti sociali, y N.d.t.). 


\section{La ciudad, patrimonio humano}

Nunca como en nuestro tiempo estamos haciendo la experiencia de la debilidad de nuestras ciudades, más aún que de su fuerza. Algunos hechos dramáticos han afectado a otras ciudades, la reaparición de oscuras amenazas y, en general, la complejidad de los procesos en curso en las grandes conurbaciones parece llevarnos a un sentimiento de turbación ante las dificultades para resistir a los desafíos de la gran ciudad.

La ciudad, sin embargo, es un patrimonio de la humanidad. Ha sido creada y sigue existiendo para proteger la plenitud de humanidad de dos peligros contrarios y disolventes: el nomadismo y el encerramiento. El primero deriva de la deslocalización que desperdiga al hombre, pivándole de un centro de identidad; el encerramiento le clausura en el clan que lo identifica pero le empobrece, dentro sólo de las paredes de lo ya conocido.

La ciudad, sin embargo, es el lugar de una identidad que se reconstruye continuamente a partir de lo nuevo, de lo diverso, y su naturaleza encarna la convergencia de las dos tensiones que enriquecen y animan la vida del hombre: el cansancio de la apertura y la debilidad del reconocimiento. San Ambrosio lo definía según la conocida fórmula: «buscar siempre lo nuevo y guardar lo que se ha conseguido»6.

\section{La ciudad y las diferencias}

Advertimos la fatiga que supone construir la ciudad de nuestro tiempo como un lugar a la vez protector y abierto, como una especie de Jerusalén celeste de muchas puertas ${ }^{7}$. Por estas puertas entran, de hecho, y han entrado muchas diferencias generadoras de desorientación. Han entrado aún antes de aquellas a que nos referimos con el prefijo extra y a las que tendemos a atribuir males que son más radicalmente epocales y culturales. Ha sido finalmente la sociedad compleja la que ha confirmado el fin de la unidad de hábitos comunes e identificadores. Ha sido la fragmentación, que le es inherente, la que ha destruido aquella que antes era una única identidad, en tantos subsistemas de la sociedad, que aspiran cada uno a reglas particulares y diversas. Aunque hoy es cierto que corremos el riesgo de desperso-

6 De paradiso 4:25.

7 Apocalipsis 21:12-13. 
nalizar la ciudad, a causa de su apertura, y de que cada sujeto que entre en ella se sienta aislado, por otra parte, la identidad se refugia, casi por miedo, en muchos grupos de afinidad, paralelos, que reivindican reglas particulares propias. Así la apertura, desarticulándose, no enriquece ya la identidad y la identidad, parcelándose, no da sentido a toda la ciudad.

Sin embargo, la ciudad conserva un papel visible de manifestación de lo humano, si es cierto que es un lugar simbólico privilegiado donde se expresa el conflicto; un espacio para desfogar los enfrentamientos ideológicos e incluso las incomodidades comunes. Por esto la ciudad paga fuertes tributos de inseguridad e incluso de sangre. Así puede originarse un espíritu de fuga de la ciudad hacia zonas limítrofes protegidas, o hacia zonas francas, para tener las ventajas de la ciudad como lugar de intercambios provechosos y eliminar las desventajas de un contacto relacional molesto. ¿Está entonces la ciudad destinada a desperdigarse en un nuevo feudalismo, compensado quizás por las impersonales relaciones mediáticas?, ¿está abocada a convertirse en un acercamiento postizo entre unacity, identificada por el catastro y por los negocios, y la diversidad de muchos a los que se permite acampar en lugares privilegiados o degradados, según los casos? Sin embargo, si el antídoto a la ciudad difícil es la pequeña ciudad monolítica, asediada por las mil ciudades diversas, la ciudad pierde su papel de identidad-apertura. Se originará entonces una falla de inseguridad que pondrá en peligro a los que estén juntos. Es ésta, en realidad, una de las características y uno de los límites de una oligarquía, no de una democracia, según Platón: «un Estado oligárquico es un Estado no unitario, sino dual: uno de pobres y otro de ricos, subsistentes entrambos en el mismo territorio, en permanente conflicto entre ellos» ${ }^{8}$.

Se evidencia por esto hoy, más que nunca, la dificultad para la gestión de la ciudad y para su gobierno político, y puede nacer la tentación de gestionarla limitándose a tener separadas a cada una de las partes que conviven en ella, mediante una especie de muros técnicos y artificiales. Pero así muere la ciudad y sobre todo muere su tarea de custodia de la plenitud de lo humano, para la que había nacido.

8 República VIII: 7.551d 


\section{La ciudad a medida de la mirada}

Por el contrario, justamente por la fuerza desu complejidad local, la ciudad permite toda una serie de relaciones conducidas bajo la mirada y a medida de la mirada, y por esto expuestas a un control ético próximo, que consiente al hombre afinar todas sus capacidades. La ciudad es cada vez menos un territorio con características peculiares, y cada vez más un mini-Estado, en el que bullen todos los problemas humanos. Por ello es palestra de construcción política general y de exaltación de la política como actividad ética arquitectónica. Tiene por su parte además la ventaja de una tradición de identidad propia. La tiene particularmente Milán -y así le es comúnmente reconocido- en el papel del trabajo, de la organización administrativa y de los servicios, de la conexión entre religión, estructuras formativas e instituciones de caridad, que la hacen un lugar fácilmente reconocible al que accede por primera vez a ella. Pero si se pierden las raíces culturales de esta identidad y sólo se busca mantener vivas las ventajas técnicas, se acaba por perder el alma de la identidad y, a la larga, incluso aquellas ventajas.

Milán no puede, en nombre de su identidad, perder su vocación a la apertura, porque ésta justamente está inscrita en su identidad, esto es en la capacidad de integración de lo nuevo y lo diferente. La acogida, como categoría general, no es para la milanesidad sólo un asunto de buen corazón y de buen sentimiento, sino un estilo organizativo de integración que huye de la mezcla de principios retóricos y acomodamientos engañosos, y se alimenta sobre todo del testimonio de los hechos. Por esto estoy contento de que sea posible, también en colaboración con el Ayuntamiento, ofrecer a la ciudad una Casa de la caridad que responda a las intenciones de un generoso benefactor milanés y permanezca como signo de acogida hacia los más desposeídos.

\section{La ciudad y la integración de lo nuevo}

La fuerza de esta ciudad está pues en una sólida identidad y en la capacidad de integrar lo nuevo, y no sólo contenerlo espacialmente dentro de sus muros. Parece como si nuestra ciudad alimentase sus raíces en aquel gran hombre de Dios, san Ambrosio ${ }^{9}$, que supo imponer su modelo de intervención en la ciudad antigua conjugando rigor y misericordia. El

9 San Ambrosio (339-397), padre de la Iglesia occidental, fue primero prefecto civil romano de la ciudad de Milán antes de ser elegido obispo de la ciudad y recibir el bautismo. Sus estudios exegéticos Hexameron y el De officiis ministrorum fueron muy relevantes (N.d.t.). 
flagelo de Ambrosio -figura incluso en el pendón del Ayuntamiento de Milán- parece presentar a un obispo que castiga los males de la ciudad. Y así es, pero Ambrosio subraya expresamente que el flagelo no es sólo para el castigo, como la verga que es directa ${ }^{10}$ (rígida) y dura, incapaz de adaptarse a las conciencias individuales, sino que es signo de persuasión ( «verga para corregir, flagelo para persuadir $»^{11}$ ). El flagelo, sin embargo, no desarticula los miembros ni los separa, como al contrario, hacen la espada y el hacha ${ }^{12}$. El flagelo produce dolor, es cierto, pero un dolor que despierta al cuerpo, invitándolo a reanimarse. La función del poder, el religioso pero también el civil, es pues persuadir aunque sea con dolor, pero no separar.

Ambrosio cuenta que la madre de Constantino, Helena, después de haber descubierto en J erusalén la cruz de Cristo, envió al primer emperador cristiano, dos clavos de la crucifixión: uno fue insertado en la diadema imperial, para significar queera la cruz la que otorgaba sustancia a la gloria, el otro fue forjado a golpes para dejar clara a los emperadores, -que antes no admitían la responsabilidad personal en sus actos de gobierno-, la obligación no de dominar a sus súbditos, sino de guiarlos («para refrenar la insolencia de los emperadores, para controlar la discreción de los señores (...) y que rigieran a los súbitos en beneficio de ellos» ${ }^{13}$ ). Setrata de suavizar los ineluctables gestos de fuerza con una paralela moderación del poder, que no es una estrategia pragmática, sino más bien un habitus de magnanimidad. Ésta permite pacificar con dignidad al más débil, sin dar una señal de que se cede ante el más fuerte.

\section{La ciudad en favor de los débiles}

Nuestro pensamiento se dirige, sobre todo, a los débiles. Es inútil forjarse ilusiones: la historia enseña que casi nunca el pan ha sido el que ha ido hacia los pobres, sino los pobres los que han ido hacia el pan. «Escogerse el huésped es envilecer la hospitalidad ${ }^{14}$, decía Ambrosio. Esto no significa una aceptación pasiva, sufrida e insensata, o la acogida sólo de aquel

10 En latín, directa, en el original.

11 «Virga ut corrigat, flagello ut suadeat», en Exp. Luc. IX:21.

12 Cfr. Sermo contra Auxentium =Epistola 75A, 17.23.

13 «t imperatorum insolentiam refrenaret, comprimeret licentiam tyrannorum (...) ut regerent sibi subditos», en De obitu Theodosii, 50.

14 Exp. Luc. VI:66 
huésped que sea similar a nosotros: el receptor magnánimo no teme al que es diferente porque está firme en la propia identidad. El verdadero problema es que nuestras ciudades, más allá de las aceleraciones inducidas por hechos contingentes, ya no están seguras de su propia identidad y de su papel humanizador, y confunden su inseguridad de fondo con una inseguridad de importación. Sin embargo la carcoma está ya en ellas y debe haber quien la combata con lucidez, viendo la ciudad como oportunidad y no sólo como dificultad. La ciudad ha de proyectarse y construirse con inteligencia y con magnanimidad, como se expresa un curioso parangón escrito por san Ambrosio: «El lugar donde un rey de la tierra quiere hacer reposar su ejército ha de ser no un pueblecito desconocido, carente de recursos, no una zona arenosa deforestada, sino una ciudad famosa por sus edificios, rica y próspera en muchos medios, o un campo feraz con verdes prados o lugares ricos en bosques y campos capaces de acoger campamentos». Dios va siempre a la vanguardia durante la marcha de su pueblo hacia la nueva ciudad ${ }^{15}$ ».

Parece a veces que la ciudad -en particular en sus miembros más poderosos- tiene miedo de los más débiles y que la política urbana tiende a buscar la tranquilidad mediante la tutela del poder. No es ésta la lección de Ambrosio, para quien la política consiste en el servicio a los más débiles. Ésta no es una invitación vagamente moralista, sino que tiene eficacia política. El miedo urbano no se puede vencer con miedos que encierren, sino con un sobreesfuerzo de participación cordial, un retorno a la ocupación activa del propio territorio y al interés por él; no con la huida y la recriminación, sino con un control social de los espacios territoriales eideales que sea más firme. El que se aísla está destinado a huir hacia el infinito, porque hallará siempre alguna complicación que le lleve a eludir el problema de la relación, como dice Ambrosio: «municipio es el deber de mantener relaciones» ${ }^{16}$.

\section{Redes de relaciones en la ciudad}

La invitación para crear lazos de solidaridad cada vez más difundidos (parentesco, amigos, grupos sociales, grupos culturales, grupos eclesiales, grupos políticos) no es sólo un capricho de almas bellas ni consiste en la creación de oasis incomunicantes. Es la única forma de vencer el miedo

15 Expositio psalmi CXVIII, HE, 14.

16 Hexameron V, serm. VIII, 21, 66. 
propio de una excepcional defensa aislada. El que toma a su cargo el bien de todos puede parecer, aparentemente, más expuesto a las presiones de los adversarios con los que dialoga y compite, pero en realidad, está protegido, como si de una coraza se tratase, por las adhesiones y la solidaridad que no le dejan inerme. De ahí deriva esa predilección, intrínseca a la doctrina social de la Iglesia, por los valores sociales, más que por aquellos individualistas o libertarios, es decir por los valores que permiten las relaciones, no por aquellos que conceden al individuo una libertad lo más extensa posible, aunque sin responsabilidad.

Buscar seguridades ante nuestros miedos, a través de las segregaciones individuales y la acumulación de recursos, parece el camino naturalmente más fácil, que se ha convertido en algo menos odioso gracias a los mecanismos financieros que ocultan las opciones económicas de fondo. Sin embargo ésta no es la receta que, según san Ambrosio, nos hará salir de la crisis. Desde siempre, en épocas de angustia, las seguridades no se basan en manifestaciones de poder, que atraen cadenas de reacciones y de envidias; sino que están inscritas en gestos de misericordia: «a misericordia no queda nunca decepcionada, sino que recibe ayuda» ${ }^{17}$. La ciudad necesita, para funcionar, gestos de entrega, no apuestas por la exclusión. En esta abnegación san Ambrosio veía revivir, en su tiempo, el valor de la donación cívica que era típica de los altos cargos de la antigua Roma y de sus virtudes. Recordaba la obligación de los espíritus fuertes de superar el estéril orgullo de casta y así reconstruir, a partir de esos valores de la abnegación, una sociedad en fase de disgregación. Sólo con la generosidad se logrará crear una mentalidad de solidaridad, sólo con la generosidad se encontrarán amigos en los momentos críticos.

Nuestra sociedad no sesiente hoy ya obligada a la atención por los últimos, interesadamente, como ocurría en el pasado, ante el miedo al furor de los pobres que ahora, reducido ya su número y su poder, ven difícil hacer oír la propia voz y encontrar una representación política. Pero nuestro encerramiento produce un mal que es aún peor que la rabia del pobre, porque es mucho más sutil: el debilitamiento del espíritu de solidaridad. Si es cierto que este debilitamiento comienza a manifestarse primero ante los lejanos y los extraños, y parece aportar ventajas a quien los excluye, este debilitamiento se aproxima después, poco a poco cada vez más, a los cercanos y penetra finalmente, por una ineluctable corriente expansiva, dentro de nosotros mismos, castigándonos más tarde cuando estemos en posiciones débiles. No

17 De officiis, III,47. 
nos podemos hacer ilusiones de pararlo fácilmente, mantenién donos a salvo fuera de nuestro círculo de intereses. Los mecanismos de la historia se reproducen inexorablemente dentro del hombre.

\section{La ciudad y sus reglas}

La búsqueda del bien para la ciudad de todos tiene reglas propias de crecimiento a través de las cuales no se puede dejar de pasar, so pena de perder la evidencia de tal bien: son las reglas del consenso de los ciudadanos, establecidas por las modalidades democráticas, y las de construcción del consenso. No son puras técnicas o puros métodos, sino la sustancia misma de un acto decisorio de libre adhesión. Pasan por el convencimiento y la paciencia, por la misma graduación de los valores, incluso por duras renuncias en nombre de una superior concordia civil, y se orienta siempre en orden a un bien más elevado.

Ambrosio que no olvida, en su función episcopal, al hombre político que fue, sabe ver el valor de la disciplina, incluso en la normativa jurídica y administrativa; el valor de las estructuras de gobierno, como los lugares en que se construye el hombre «de los deberes». Él comprende la importancia de la gradualidad de las leyes y del ejemplo del más poderoso. En esto acoge la lectura estoica, ciceroniana, del paso de la ética de los deberes a la ética de la virtud perfecta, que es la disposición adquirida para hacer el bien autónomamente, y no bajo una dirección heterónoma. Pero también en el paso entre moral y mística, san Ambrosio insinúa, incluso dentro de las reglas o esfuerzos de la ética, las razones del fin unitivo: las reglas de la ética, también y sobre todo la pública, imponen al hombre aquellas directrices que responden a su naturaleza y a su capacidad de acción y de realización de sí mismo. La ciudad puede desentenderse del frío oficio de acoger el mero principio de la estandarización de las reglas y de una democracia puramente formal en la que rige el principio abstracto que pretende quetodos somos iguales, incluso aquellos que por razones históricas y de humanidad son profundamente diversos: los edificios de la ciudad -dice Ambrosio- «son los mandamientos altos y los más altos... divididlos bien ${ }^{18}$, distribuyéndolos según las capacidades de cada cual, a tenor de las posibilidades que cada uno tenga de comprenderlos con las propias fuerzas ${ }^{19}$.

18 Salmo 47/48:14.

19 Explanatio psalmi XLVII, 24. 
La posibilidad de ver, en la ciudad, el rostro amigo del poder debería contribuir a promover una política defensora de aquella amistad que, en el ámbito civil, toma el nombre de concordia y que se ocupa no sólo de realizar el programa establecido con los propios amigos, sino del terreno común que existe entre estos proyectos y los del otro, es decir del «enemigo». No se trata de tener ninguna nostalgia del trasnochado y deletéreo consociativismo ${ }^{20}$ que hemos conocido, resultado de los juegos de poder. Hay que pensar más bien en la provechosa mediación entre valores, que tiene que ser constante si se quiere que en la ciudad no se cultive el germen de la revancha rencorosa y de la conflictividad perenne. Remitiéndonos incluso a la reciente Asamblea de la Conferencia Episcopal de la Iglesia italiana, debemos reafirmar que han de buscarse todos los signos de comunión dentro de las fuerzas políticas. ¿Qué terreno más provechoso que la ciudad, lugar complejo pero en el que permanece un ethos más compartido y un conocimiento menos mediado? La ciudad es un órgano político estrechamente identificado, en un territorio controlable por todos. También la Iglesia, en su misma implantación, privilegia el lugar particular, respecto a las agregaciones supralocales fruto de elecciones individuales: por ello justamente se habla de Iglesia «ocal». Algunos mecanismos son comunes, porque el mundo que ha de ser salvado es aquel con el que continuamente estamos en relación, en el que se mueve la variada riqueza de la vida de un pueblo que es nuestro prójimo más cercano. La ciudad, pues, tiene, mucho más que la aldea y con bastante diferencia con los simples grupos de amigos, la característica de la diversidad interactuante que busca crecer en el conjunto.

\section{Los cristianos y la ciudad}

En este momento quisiera decir, también en cuanto obispo, una palabra dirigida expresamente a los cristianos en la ciudad. Para ellos, la invitación a la búsqueda común de la concordia se hace más presurosa, en particular para los políticos a quienes gusta definirse cristianos, a fin de que puedan, dentro de las distintas fuerzas, representar el vínculo de una sociedad que está buscando fatigosamente su estabilización civil, puesto que ellos son portadores del ethos histórico más connatural a nuestro pueblo, el que en

20 Fenómeno político italiano posterior a la Segunda Guerra Mundial, consistente en el pactismo partitocrático que tendía a anular las diferencias, legítimas y necesarias, en el debate político, sofocando el auténtico pluralismo político. (N.d.t.) 
mayor medida le proporciona identidad. Nos gusta imaginar a los cristianos acogidos en formaciones de horizontes éticos diferenciados, sea por su representatividad histórica, sea porque garantizan el desmantelamiento de la rigidez de cada una de las fuerzas en favor de lo que de común tienen con todos. Espero que les sea otorgado ese pleno reconocimiento civil, que es justo por su sensibilidad hacia la comunión y su capacidad conexa para actuar como elementos que preservan a una ciudadanía, todavía frágil y conflictual, de las caídas en la rigidez maniquea. El cristiano debe interpretar en la ciudad la alta tarea histórica de crear un tejido común de valores sobre los que pueda legítimamente tejerse la trama de diferencias, nunca más devastadoras. Es deseable que esto ocurra, tanto en zonas propias de reflexión y de traducción antropológica de los propios valores de fe (una operación como ésta podría interpretar genuinamente, al menos, algunos aspectos del proyecto cultural de la Iglesia italiana), como haciéndolos brotar dentro de los lugares de las distintas pertenencia políticas, demostrando que se pueden ocupar a pleno título, como católicos, de los problemas de todos, no sólo con una preocupación confesional.

No vemos afinidad con la concepción cristiana en una política que aísla a los contendientes y les hace confrontarse entre ellos sólo en los momentos electorales. Nos gusta pensar que sea posible una política que, aún respetando papeles y responsabilidades diversas, sea perennemente dialógica, porque vale en ella la regla del consenso y que, ni siquiera éste, es un dato sólo electoral, sino del que el poder tiene continuamente necesidad para legitimarse.

\section{La ciudad de los honestos y de los iguales}

Permítaseme, finalmente, indicar, más en general, qué camino político es eficaz y cuál es el proceso para dar fuerza y amabilidad a una existencia vivida en el respeto de las reglas, mostrando que una vida humilde y paciente, respetuosa de las leyes y ajena a la prepotencia, no es una conducta cobarde, sino humana y fuerte. Pero mientras nuestra sociedad estime más a los «tramposos» que tienen éxito, un agua cenagosa seguirá alimentando el molino dela ilegalidad e incluso, ciertamente, de la difusa microcriminalidad. Existe otro efecto, y quizá más grave: el que, quitando estima social a la honestidad, consiste en debilitar el sentido cívico, especialmente el de los jóvenes y el de los más expuestos a la instrumentalización; y que se cultive, incluso en la industriosa Milán, un tipo de cuadrilla criminal atraída por la 
ganancia fácil. Una tarea cultural urgente, que hace coincidir a la ciudad en sus decisiones políticas con la Iglesia en su función formativa, es en ese caso alimentar un movimiento de restitución de estima social y de prestigio por el comportamiento honesto y altruista, aunque austero y pobre: «qué afortunada es la ciudadanía que cuenta con muchísimos justos $»^{21}$. Repasando acaso, si fuese necesario, los criterios con los que la sociedad -y quizá la propia Iglesia- concede favores y atenciones, criterios que, demasiado a menudo, premian a los poderosos de este mundo.

La ciudad evidencia las diferencias y estimula a la política en su principal papel de promoción de los diferentes, de forma particular de los más humildes, hasta que puedan alcanzar una sustancial igualdad. Si es tarea de la ciudad la promoción de todos los hombres, ésta se realiza no con una abstracta equidistancia, sino con opciones preferenciales costosas a lo largo de la historia. Sólo estas construyen un hábito útil para la promoción de la multitud, y no se limitan a confiar la creación de una ciudad amable a gestos de sensibilidad individual, por otra parte siempre meritorios. Estamos convencidos que la ciudad de Ambrosio, que ha inscrito en su código la costumbre de traducir en hechos institucionales cualquier acontecimiento nuevo que se produzca en ella, podrá encontrar la modalidad para hacer una traducción civil participada y correcta de las emergencias humanas de nuestro tiempo y anticipar incluso soluciones más generales y compartidas.

Es con esta confianza y con este deseo que, mientras sigo agradeciendo el honor que se me ha concedido, expreso los mejores votos para el futuro de esta ciudad por la que, tened la certeza, seguiré rezand o e interesándome con afecto y aprecio, incluso en los más lejanos lugares, quizá desde aquella ciudad de J erusalén que recoge en sí las esperanzas, los padecimientos y los ideales de la entera humanidad.

21 De Cain II, 12. 